\title{
A Study on Crack Depth Measurement in Steel Structures Using Image-Based Intensity Differences
}

\author{
Ju-Yeong Jung $\mathbb{D},{ }^{1}$ Hyuk-Jin Yoon $\mathbb{D D}^{2},{ }^{2}$ and Hyun-Woo Cho ${ }^{3}$ \\ ${ }^{1}$ Korea Railroad Research Institute, Uiwang-si 16105, Republic of Korea \\ ${ }^{2}$ Korea Railroad Research Institute, University of Science and Technology, Uiwang-si 16105, Republic of Korea \\ ${ }^{3}$ University of Science and Technology, Uiwang-si 16105, Republic of Korea
}

Correspondence should be addressed to Hyuk-Jin Yoon; scipio@krri.re.kr

Received 23 November 2017; Accepted 8 March 2018; Published 3 April 2018

Academic Editor: Venu G. M. Annamdas

Copyright (c) $2018 \mathrm{Ju}$-Yeong Jung et al. This is an open access article distributed under the Creative Commons Attribution License, which permits unrestricted use, distribution, and reproduction in any medium, provided the original work is properly cited.

This paper seeks to propose an image-based noncontact testing method in crack depth measurement. To this end, it predicted the crack depth using the intensity values of cracks and verified its validity. To analyze the intensity values of cracks, eight stainless steel specimens with an increase in crack depths ranging from 0 to $17.5 \mathrm{~mm}$ at an average of $2.5 \mathrm{~mm}$ were fabricated, and a contrast index was attached to the center of the crack of the specimens painted with black matte spray for accurate analysis. Through various experiments, it was found that the intensity values of the cracks which decrease with the depth of the cracks were inductively formulated, and the average error was about $15 \%$ when the crack depth predicted by the empirical equation was compared with the actual crack depth. In addition, the validation of the intensity reduction equation obtained by the inductive method was verified, and it was confirmed that the crack depth can be predicted by the intensity value of the crack.

\section{Introduction}

Various cracks that occur in structures cause appearance degradation as well as decreased strength of the structures and may lead to casualties and property damages if proper maintenance work is not done beforehand. Therefore, early detection and repair of cracks in structures is a very basic and important procedure to prevent social loss. The research using image processing is the most representative study regarding the determination of size of cracks in structures, and its measurement accuracy is also high [1-3]. Meanwhile, the research on the crack depth measurement mainly deals with nondestructive testing (NDT), which is largely divided into contact and noncontact testing methods. However, the crack depth measurement technology requires complicated test equipment and experimental procedures, and the variety of crack shapes causes accuracy problems in field applications.

Nondestructive testing, which is an inspection method related to the measurement of crack depth in structures, generally refers to the inspection technique that allows materials or components to be examined without changing their original shapes or functions, and it also refers to all inspection methods to examine the properties, conditions, and internal structures of a product without disassembling or destroying it. Nondestructive testing methods include radiographic testing (RT), ultrasonic testing (UT), magnetic practice testing (MT), penetrant testing (PT), eddy current testing (ET), leak testing (LT), and infrared thermography (IRT), and so on, and the demand is fast growing with the development of high-valueadded industries [4]. Among the various nondestructive techniques that can measure the depth of cracks, the noncontact testing typically includes eddy current testing [5-7] and infrared thermography [8-10], and it is the inspection method using the characteristics that the size and depth of the crack affect the formation of the temperature distribution of an object. However, the eddy current testing has a disadvantage in that a probe must be located very close to the surface of the object and is very sensitive to the surface roughness. In addition, the infrared thermography has a problem in that the influence of absorption scattering must be removed from the background noise and propagation path to prevent deviations in the detection of defects since the deviation of the emissivity 


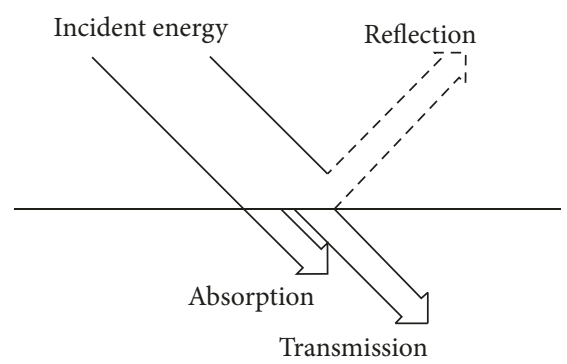

Single reflection on a surface

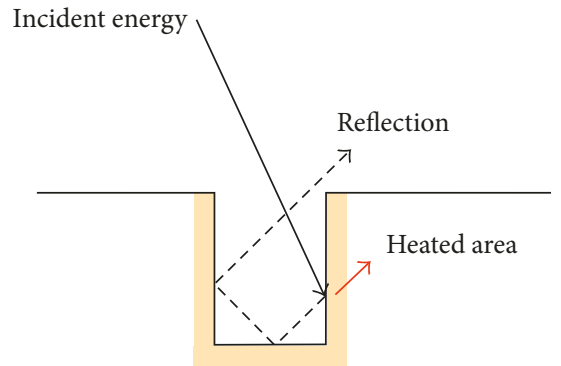

Multiple reflection in a crack

Figure 1: Multiple reflections of light in a crack.

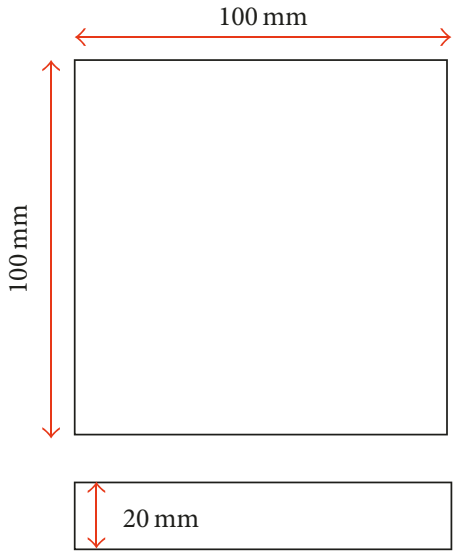

Uncracked specimen
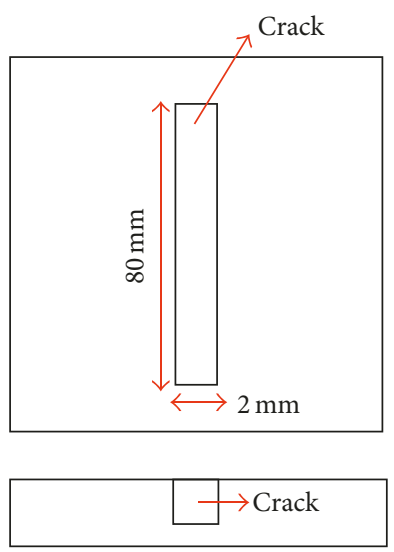

Cracked specimen
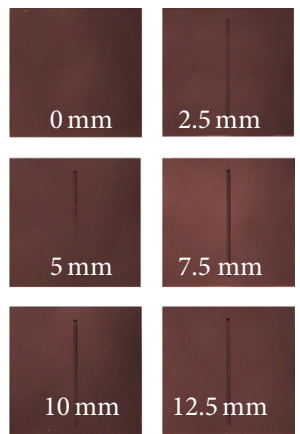

$15 \mathrm{~mm}$

$17.5 \mathrm{~mm}$

FIGURE 2: Dimension of test specimens painted with black matte spray.

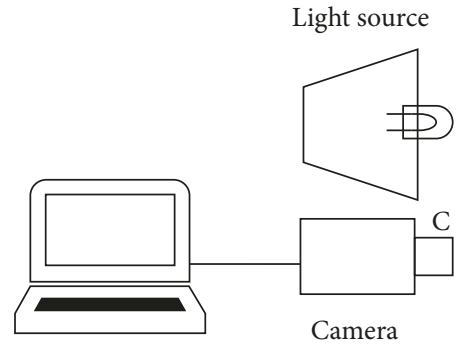

PC

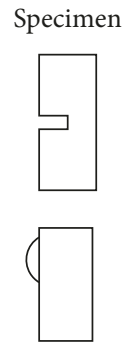

Illuminometer

FIgURE 3: Schematic of the experimental setup.

varies greatly depending on the surface state of an object. The noncontact testing is relatively free from restrictions on the shape of the object, as compared to the contact testing. However, due to the abovementioned disadvantages, especially the reliability uncertainties caused by the surface state of the object lead to a problem in the actual field applications.

This study uses much simpler experimental equipment than the eddy current test or infrared thermography, so it can save the cost and time required for the experiment. And it is very easy to carry out the postprocessing for measuring the crack depth because it requires only the intensity value in the extracted images. This paper investigated the relationship between crack depth and intensity to resolve the disadvantages of the noncontact crack depth inspection method which is restricted by the surface state of the object and propose an image-based crack depth measurement method. For experiments, stainless steel specimens with different depths were fabricated, and the experiments were conducted in an environment with limited illumination to confirm the intensity differences. The intensity value that decreases in a crack was calculated using an empirical equation obtained through a series of experiments, and the crack depths of the specimens were predicted through the intensity analysis of cracks in each specimen. 

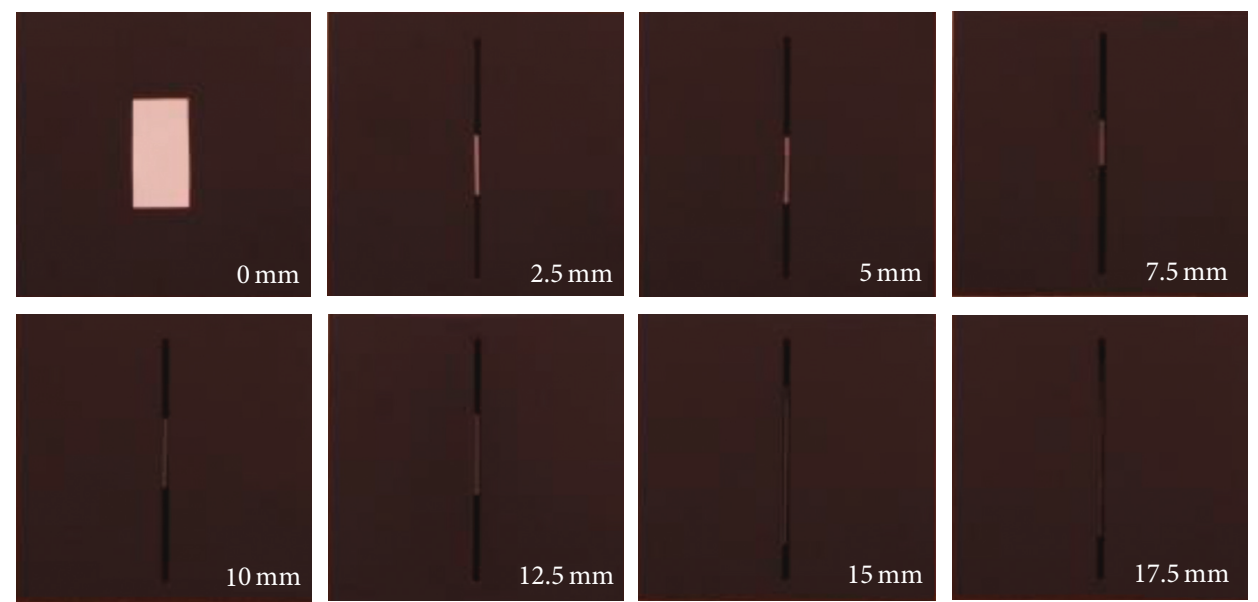

FIgURE 4: Test specimens painted with black matte spray and contrast index attached to the center of the cracks.

TABLE 1: Equipment specifications.

\begin{tabular}{|c|c|c|}
\hline Apparatuses & Items & Specifications \\
\hline \multirow{2}{*}{ Camera } & Resolution & $6000 \times 4000$ \\
\hline & Sensor type (size) & APS-C $(23.2 \times 15.4 \mathrm{~mm})$ \\
\hline \multirow{2}{*}{ Illuminometer } & Receptor & Silicon photocell \\
\hline & Measuring range & 0.01 to $299,900 \mathrm{~lx} ; 0.001$ to $29,990 \mathrm{fcd}$ \\
\hline \multirow{2}{*}{ Lamp } & Power & $1000 \mathrm{~W} / \mathrm{s}$ \\
\hline & Color temperature & $3200^{\circ} \mathrm{K}$ \\
\hline
\end{tabular}

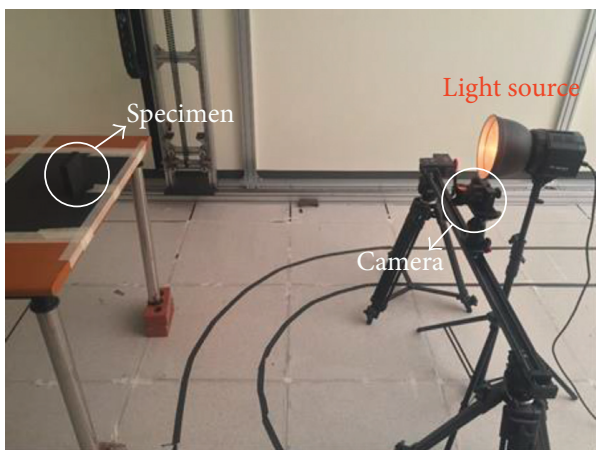

(a)

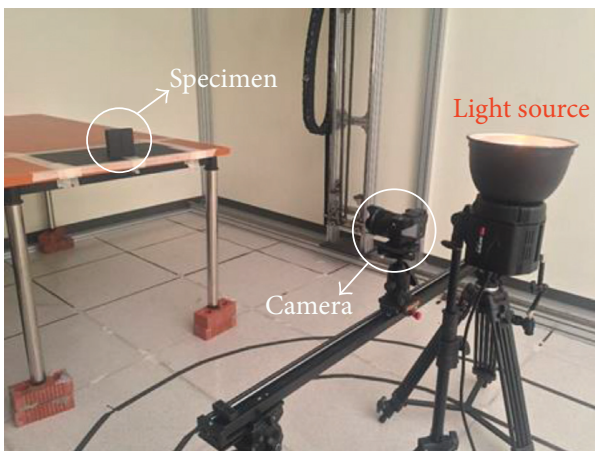

(b)

Figure 5: Experimental setup for (a) direct and (b) indirect lighting.

TABLE 2: Illuminance level depending on distance.

\begin{tabular}{|c|c|c|c|c|c|c|c|c|c|}
\hline \multirow{2}{*}{ Distance $(\mathrm{m})$} & \multirow{2}{*}{ Illuminance $(\mathrm{lx})$} & \multicolumn{8}{|c|}{ Intensity values $(0 \sim 255)$} \\
\hline & & $0 \mathrm{~mm}$ & $2.5 \mathrm{~mm}$ & $5 \mathrm{~mm}$ & $7.5 \mathrm{~mm}$ & $10 \mathrm{~mm}$ & $12.5 \mathrm{~mm}$ & $15 \mathrm{~mm}$ & $17.5 \mathrm{~mm}$ \\
\hline 1 & 2.39 & 236 & 223 & 223 & 224 & 219 & 219 & 216 & 209 \\
\hline 2 & 1.89 & 232 & 218 & 221 & 219 & 225 & 221 & 217 & 220 \\
\hline 3 & 1.55 & 211 & 177 & 181 & 173 & 186 & 179 & 184 & 177 \\
\hline 4 & 0.83 & 201 & 188 & 177 & 168 & 176 & 170 & 176 & 172 \\
\hline 5 & 0.53 & 206 & 170 & 168 & 168 & 170 & 164 & 165 & 162 \\
\hline 6 & 0.43 & 200 & 157 & 154 & 139 & 139 & 136 & 142 & 144 \\
\hline 1 & 3670 & 238 & 255 & 255 & 255 & 255 & 255 & 255 & 255 \\
\hline 3 & 640 & 226 & 210 & 203 & 224 & 223 & 216 & 207 & 225 \\
\hline
\end{tabular}




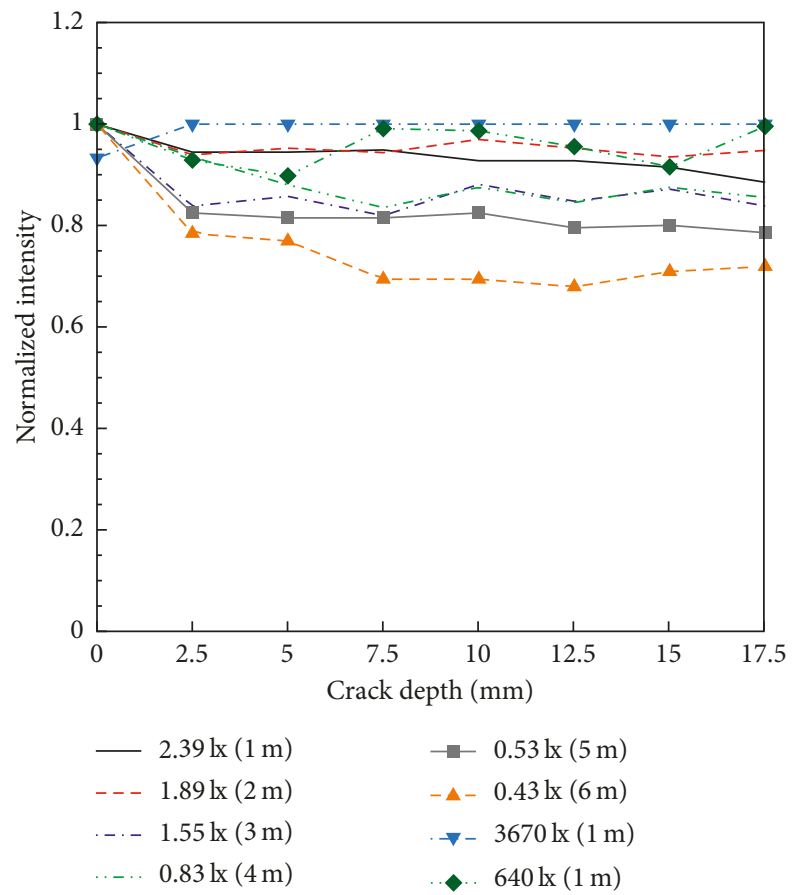

FIGURE 6: Intensity value of cracked area under direct lighting condition.

TABLE 3: Intensity value of cracked area depending on illuminance under indirect lighting condition.

\begin{tabular}{lcccccccc}
\hline \multirow{2}{*}{ Illuminance (lx) } & \multicolumn{7}{c}{ Intensity values (0 255) } \\
& $0 \mathrm{~mm}$ & $2.5 \mathrm{~mm}$ & $5 \mathrm{~mm}$ & $7.5 \mathrm{~mm}$ & $10 \mathrm{~mm}$ & $12.5 \mathrm{~mm}$ & $15 \mathrm{~mm}$ & $17.5 \mathrm{~mm}$ \\
\hline 244 & 188 & 120 & 96 & 69 & 52 & 50 & 45 \\
144 & 181 & 119 & 97 & 65 & 53 & 51 & 44 \\
51 & 176 & 113 & 92 & 63 & 50 & 46 & 46 \\
2 & 198 & 136 & 108 & 84 & 66 & 60 & 52 \\
\hline
\end{tabular}

\section{Principle of Image-Based Intensity Difference in Crack Depth Measurement}

In physics, the intensity of light is inversely proportional to the square of the distance from a light source as shown in (1), which is called the inverse-square law. The light from a point source can be put in the following form:

$$
E=\frac{I}{R^{2}}
$$

where $E$ is called illuminance, $R$ is the distance, and $I$ is called pointance. In this study, the factors affecting the intensity value of the crack are the direction and intensity of the light source, the distance between the light source and specimen, and the depth of the specimen crack. When the distance between the specimen and light source, and the intensity of the light source are fixed, the amount of the light received by the crack is reduced by the inverse-square law [11-13], and the theoretical value can be obtained by (1). In addition, cracks which are artificially generated in this study can be seen as black body cavities, and the amount of light absorbed by these black body cavities is obtained by the

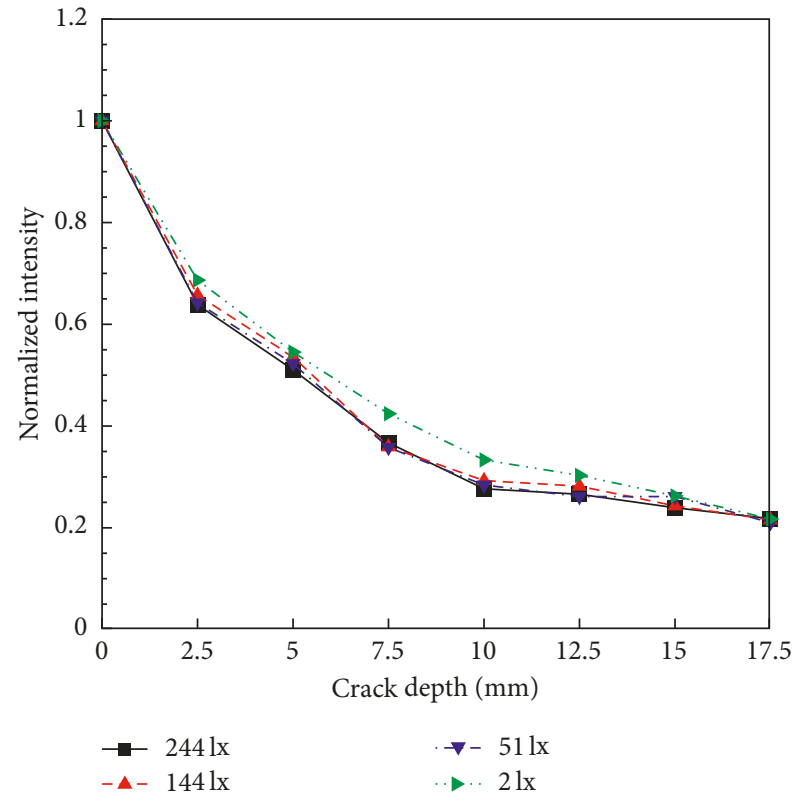

FIGURE 7: Intensity value under indirect lighting condition. 
TABLE 4: Ideal experimental data.

\begin{tabular}{lcccccccc}
\hline \multirow{2}{*}{ Illuminance $(\mathrm{lx})$} & \multicolumn{7}{c}{ Intensity values $(0 \sim 255)$} \\
& $1(0 \mathrm{~mm})$ & $2(2.5 \mathrm{~mm})$ & $3(5 \mathrm{~mm})$ & $4(7.5 \mathrm{~mm})$ & $5(10 \mathrm{~mm})$ & $6(12.5 \mathrm{~mm})$ & $7(15 \mathrm{~mm})$ & $8(17.5 \mathrm{~mm})$ \\
\hline 468 & 124 & 65 & 49 & 35 & 27 & 24 & 22 & 17 \\
\hline
\end{tabular}

combined action of the light reflected and absorbed inside the crack and the inverse-square law as shown in Figure 1. Due to this principle, as the depth of the crack increases, the amount of the absorbed light increases. From the result, it is determined that each specimen shows different intensity values.

In this paper, the empirical equation obtained from the experiments was used to calculate the intensity of the light reduced by multiple factors in the black body cavity, and the crack depth was predicted using the intensity value of the crack.

\section{Experimental Setup}

The specimen used in the experiment was made of stainless steel Grade 34 materials. As shown in Figure 2, the size of the specimen is 100 by 100 by $20 \mathrm{~mm}$, and a crack with $2 \mathrm{~mm}$ in width and $80 \mathrm{~mm}$ in length is in the middle of the specimen. The depth of the crack is deepened by $2.5 \mathrm{~mm}$ from 0 to $17.5 \mathrm{~mm}$, and a total of eight test specimens were fabricated. The fabricated specimens were painted with a black matte spray to minimize the unnecessary reflection of the light from the crack and the emissivity of the spray is 0.9. The schematic of the experimental setup is shown in Figure 3.

The experiment was designed to determine the intensity differences depending on the crack depths and predict the depths of the cracked specimens with the use of the differences. However, the amount of paint in the cracked area was not constant, and the unevenly painted area can cause an error in the intensity value of the cracked area. To address this problem, an index indicating a constant intensity value is needed. In this paper, a white paper made using Minolta CR-200 colorimeter was attached to the cracked area as a uniform intensity value index as shown in Figure 4, and the experiment was conducted under two conditions where the specimen was directly illuminated and indirectly illuminated by the light source. In addition, an experiment to obtain empirical equations and an experiment for verification of the empirical equations were performed additionally, and the validity of the study was verified at various illuminations. Table 1 shows the detailed specifications of the equipment used in the experiments.

\section{Experimental Results and Discussion}

\subsection{Experimental Results under Direct and Indirect Lighting Conditions}

4.1.1. Direct Lighting Condition. The experiment was conducted to analyze the intensity value of the crack for each specimen in the case where the specimen was directly

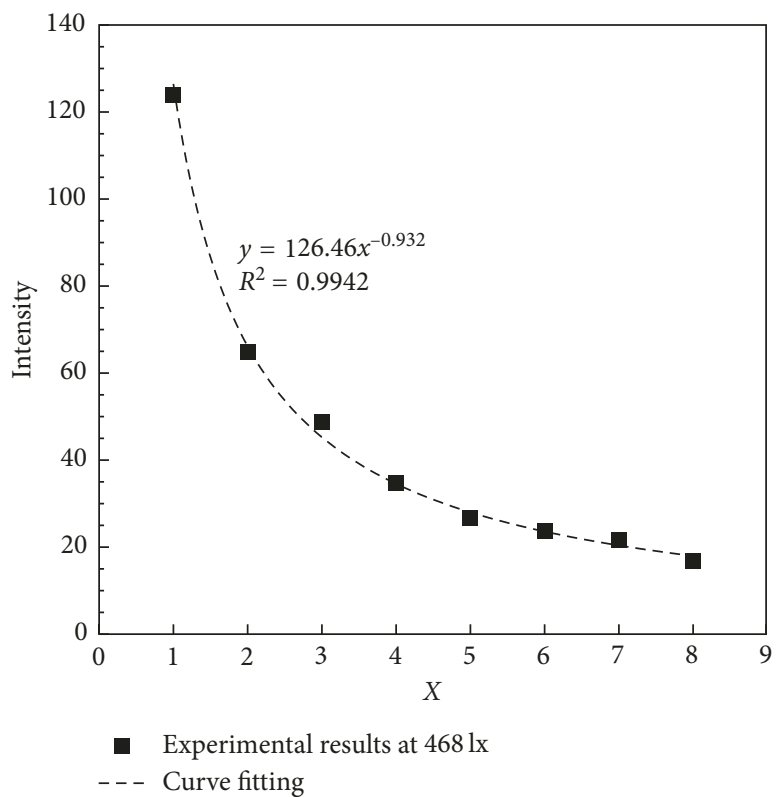

Figure 8: Approximate functions of intensity values.

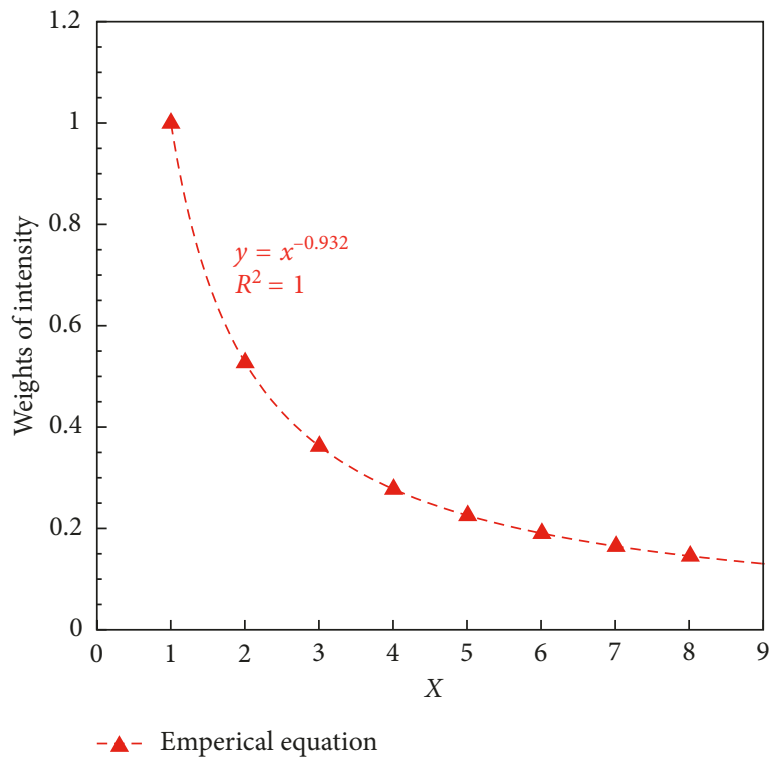

FIGURE 9: Intensity reduction caused by black body cavity.

illuminated by the light source as shown in Figure 5(a). Table 2 shows that the distance between the light source and the specimen was increased by $1 \mathrm{~m}$ from 1 to $6 \mathrm{~m}$ under low and high illuminance conditions. It was confirmed that the intensity value of the crack did not show uniform patterns under low illuminance condition, and the intensity value was 
TABLE 5: Experimental conditions at 2 468 lx.

\begin{tabular}{lcccccccc}
\hline \multirow{2}{*}{ Illuminance (lx) } & \multicolumn{7}{c}{ Intensity values $(0 \sim 255)$} & \\
& $0 \mathrm{~mm}$ & $2.5 \mathrm{~mm}$ & $5 \mathrm{~mm}$ & $7.5 \mathrm{~mm}$ & $10 \mathrm{~mm}$ & $12.5 \mathrm{~mm}$ & $15 \mathrm{~mm}$ & $17.5 \mathrm{~mm}$ \\
\hline 468 & 124 & 65 & 49 & 35 & 27 & 24 & 22 \\
376 & 127 & 65 & 49 & 35 & 32 & 26 & 21 \\
325 & 113 & 56 & 42 & 30 & 21 & 19 & 17 \\
212 & 124 & 68 & 51 & 37 & 25 & 24 & 21 \\
140 & 146 & 80 & 59 & 47 & 37 & 29 & 27 \\
67 & 125 & 69 & 50 & 39 & 30 & 25 & 23 \\
2 & 105 & 60 & 45 & 35 & 26 & 23 & 23 \\
\hline
\end{tabular}

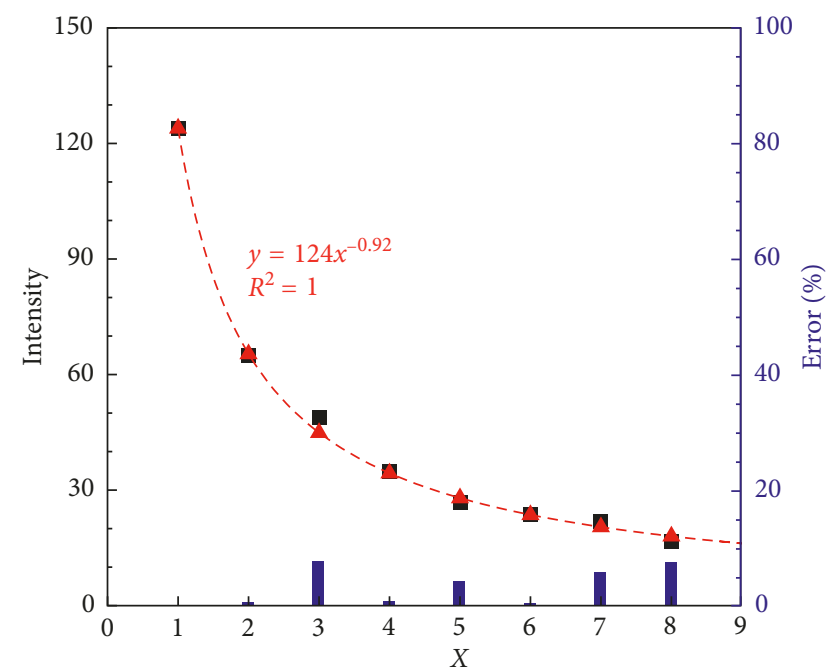

- Experimental results (468 lx)

- $\mathbf{-}$ - Predicted values

- Error

(a)

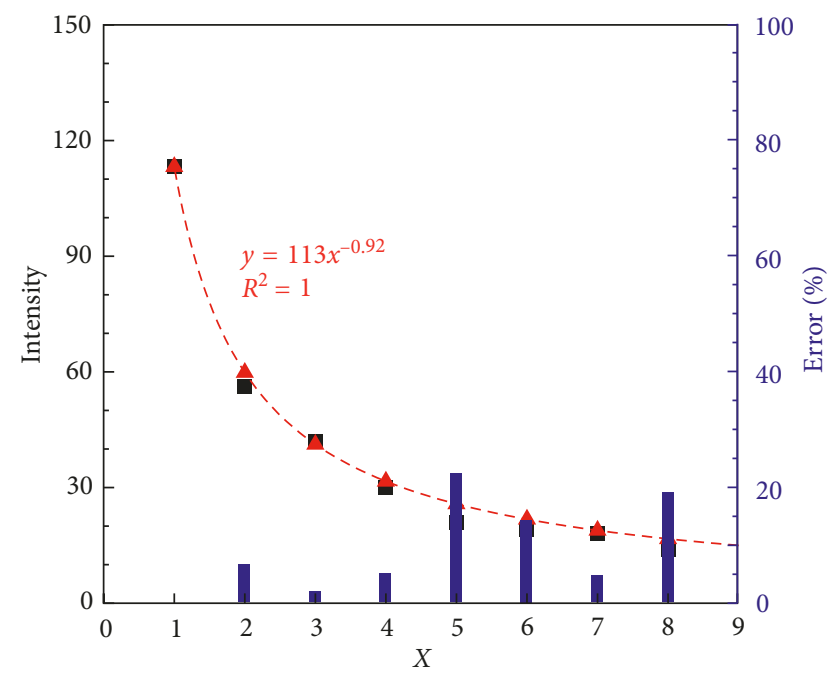

- Experimental results (325lx)

- $\mathbf{\Delta -}$ Predicted values

- Error

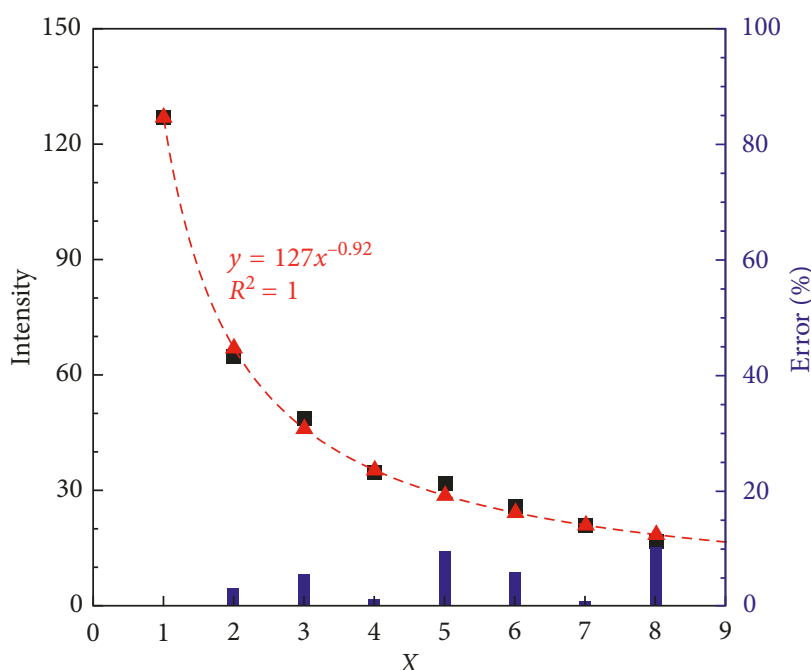

- Experimental results (376 lx)

- $\Delta$ - Predicted values

I Error

(b)

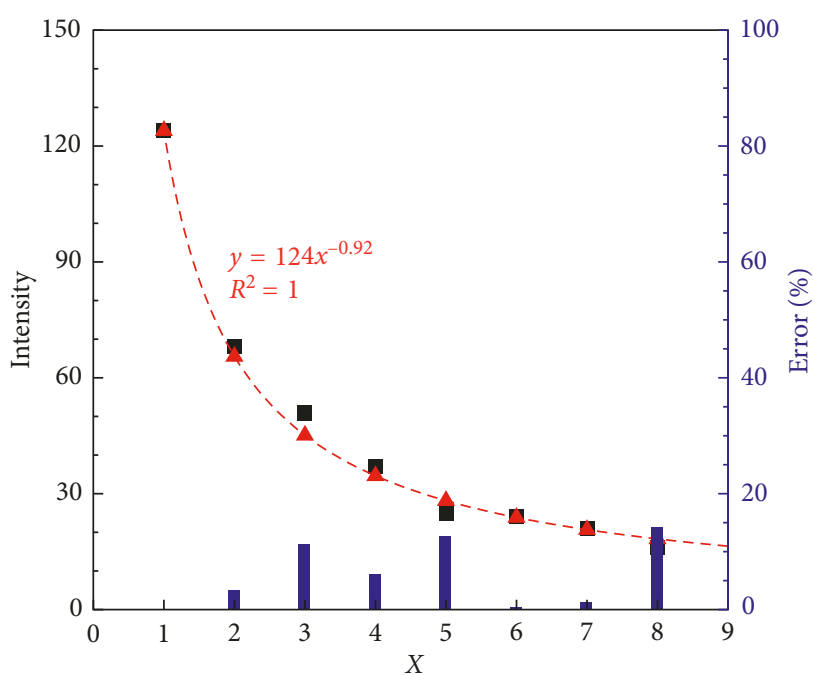

- Experimental results (212 lx)

- $\mathbf{\Delta -}$ Predicted values

I Error

(c)

FIgUre 10: Continued. 


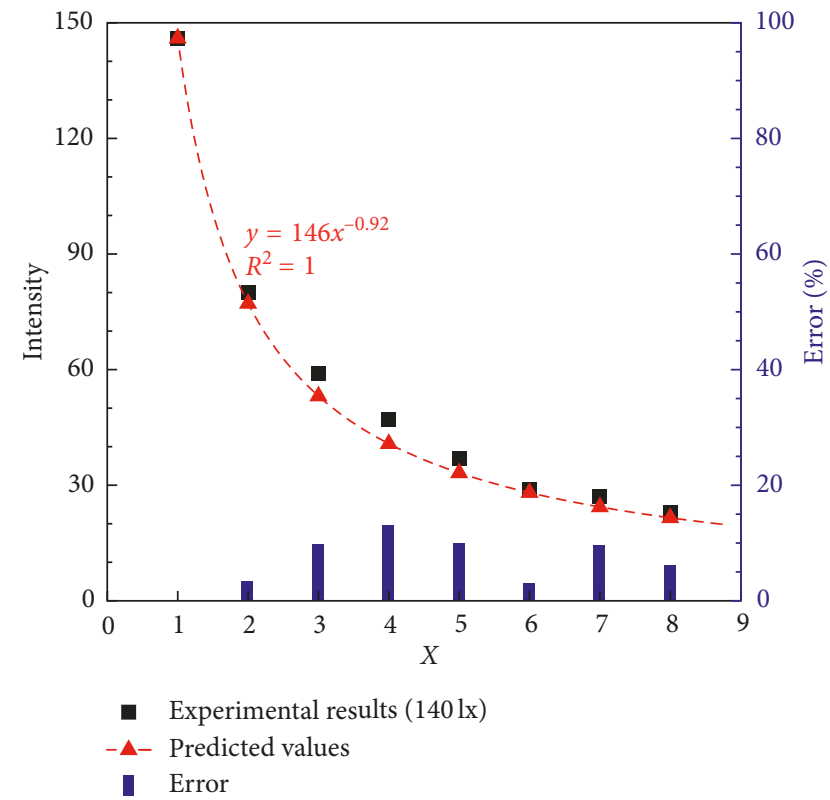

(e)

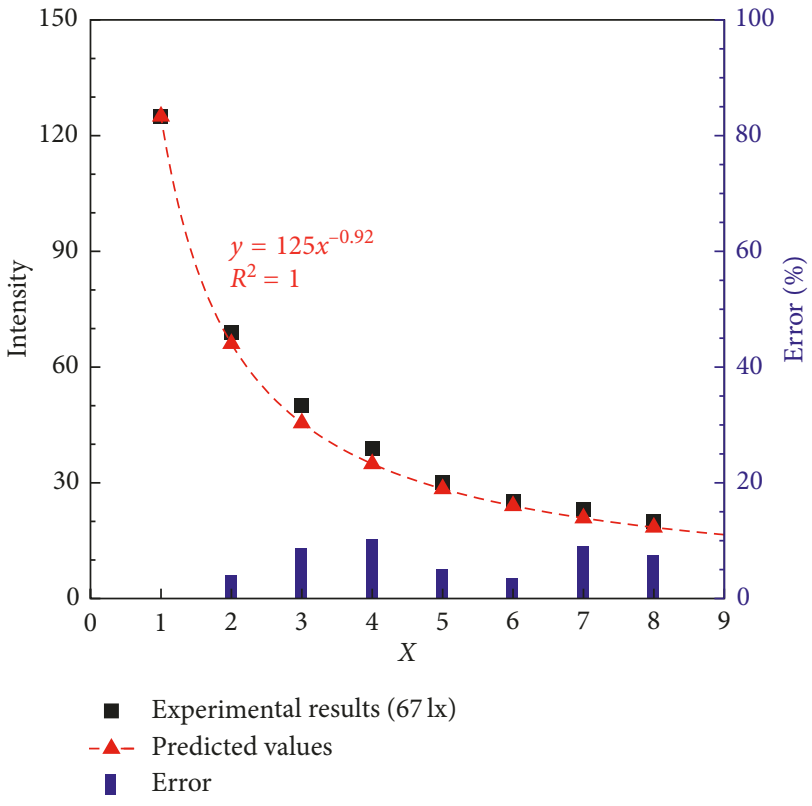

(f)

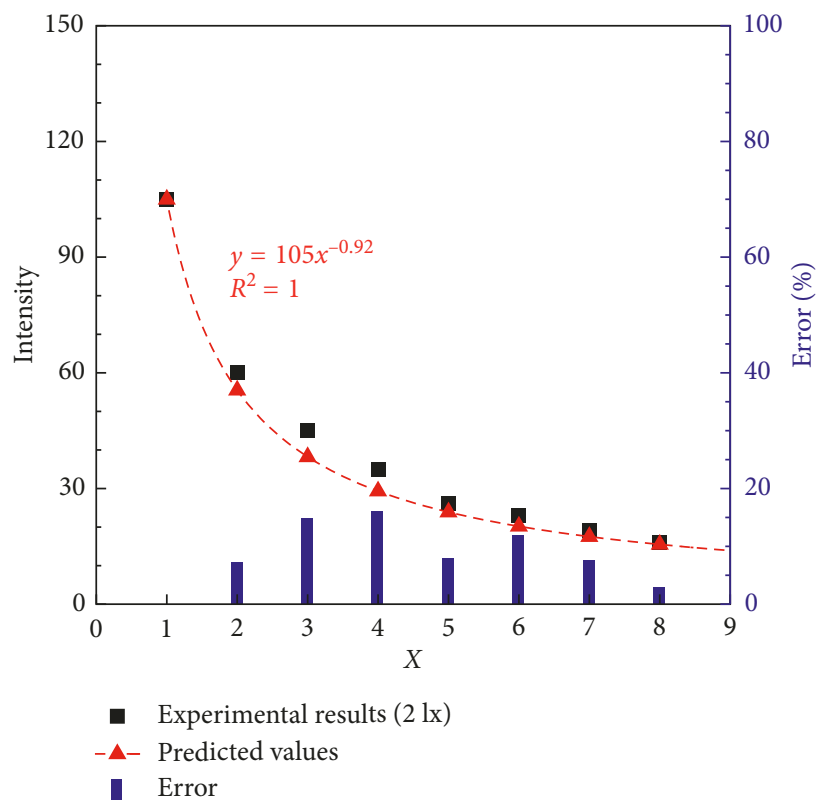

(g)

FIgURE 10: Plots of the experimental results for the validation of empirical equations.

constant at the time of incident luminosity exceeding the intensity value reduced by the crack of the specimens under high illuminance condition. In addition, the intensity value of the uncracked specimen was lower than that of the cracked specimen at $3670 \mathrm{~lx}$, which is the highest illuminance because the light of high illuminance incident on the cracked specimen generates multiple reflections inside the crack, but a single reflection occurs in the uncracked specimen. These results confirmed that the experiment by direct lighting is not suitable for the analysis of intensity values depending on the crack depths, regardless of the illuminance. As shown in Figure 6, the maximum intensity value for each specimen was normalized to have a value of 1 for a comparison of the experimental results.

4.1.2. Indirect Lighting Condition. The specimen was irradiated indirectly with lighting upward as shown in Figure 5(b). The experiment was conducted in the illuminance as shown in Table 3, and it can be confirmed that the intensity value trends for each specimen decrease at a certain rate. In addition, the two experiments found that the trends of the intensity values vary depending on the lighting direction despite similar illuminations. Figure 7 shows that the maximum intensity value 
TABLE 6: Experimental results of verification on empirical equations.

\begin{tabular}{lccccccccc}
\hline \multirow{2}{*}{ Illuminance (lx) } & \multicolumn{9}{c}{ Crack depth (mm) } \\
& Actual depth & 2.5 & 5 & 7.5 & 10 & 12.5 & 15 & 17.5 & Average error (\%) \\
\hline 468 & & 2.54 & 4.36 & 7.39 & 10.61 & 12.40 & 13.88 & 19.17 & 5.73 \\
376 & 2.68 & 4.54 & 7.65 & 8.69 & 11.52 & 15.18 & 19.75 & 7.62 \\
325 & & 2.86 & 4.83 & 8.05 & 13.07 & 14.86 & 15.91 & 21.70 & 15.02 \\
212 & Predicted depth & 2.30 & 4.07 & 6.81 & 11.75 & 12.40 & 14.73 & 20.65 & 10.56 \\
140 & & 2.31 & 4.19 & 6.07 & 8.62 & 11.99 & 13.16 & 16.14 & 11.56 \\
67 & & 2.27 & 4.27 & 6.37 & 9.29 & 11.88 & 13.24 & 15.82 & 10.33 \\
2 & & 2.09 & 3.78 & 5.75 & 8.90 & 10.52 & 13.53 & 16.82 & 14.93 \\
\hline
\end{tabular}

Table 7: Experimental images of Figure 10.

\begin{tabular}{|c|c|c|c|c|c|c|c|c|}
\hline \multirow{2}{*}{ Illuminance (lx) } & \multicolumn{8}{|c|}{ Crack depth } \\
\hline & $0 \mathrm{~mm}$ & $2.5 \mathrm{~mm}$ & $5 \mathrm{~mm}$ & $7.5 \mathrm{~mm}$ & $10 \mathrm{~mm}$ & $12.5 \mathrm{~mm}$ & $15 \mathrm{~mm}$ & $17.5 \mathrm{~mm}$ \\
\hline 468 & & & & & & & & \\
\hline 376 & & & & & & & & \\
\hline 325 & & & & & & & & \\
\hline 212 & & & & & & & & \\
\hline 140 & & & & & & & & \\
\hline 67 & & & & & & & & \\
\hline 2 & & & & & & & & \\
\hline
\end{tabular}

for each specimen was normalized to have a value of 1 as in Figure 6.

4.2. Deduction of Empirical Equations. Empirical equations to be applied to this study should have the same decrease rate of intensity value of the cracked area due to the black body cavity even when the illuminance is changed. The experiment was conducted dozens of times to set up empirical equations after obtaining ideal experimental values, and the empirical equation representing the brightness reduction due to the black body cavity was formulated through the inductive method. The first step of a full-scale experiment is to obtain the intensity value of each specimen according to the illuminance. The experiment was conducted using indirect lighting at various illuminations, and the optimum condition was determined by comparing the results after obtaining the intensity values of each specimen. The intensity values according to the crack depths in this experiment take the form of power, and the most ideal intensity values and illuminance are shown in Table 4 and Figure 8.

The calculation of the empirical equations starts with the intensity value of the uncracked specimen. The intensity value of the uncracked specimen taken at a constant illumination is the initial intensity value incident on the cracked specimen, and the reduction caused by the black body cavity is not applied to this value. Equation (2) was used to consider the intensity reduction caused by the cracked area, and the intensity reduction according to the depth of the cracked area with a width of $2 \mathrm{~mm}$ and a length of $80 \mathrm{~mm}$ was represented by the following equation: 


$$
S_{\text {ini }} \times f(x)=g(x),
$$

where $S_{\text {ini }}$ is the initial intensity value, $f(x)$ is the intensity value reduced by the black body cavity, and $g(x)$ is the experimental value. Figure 9 shows the intensity reduction function $(f(x))$ by the black body cavity, and the depth of the crack can be predicted by the numerically approximated empirical equation and the intensity value of the uncracked specimen. In other words, since the initial intensity value is substituted into the intensity reduction function by the depth of the black body cavity, it is possible to obtain the intensity value according to the crack depth. Therefore, if only the initial intensity value of the crack-free area is measured, the crack depth according to the intensity value can be predicted through the function obtained by the experiment. In addition, since the approximate function of the above intensity value cannot include 0 in the $x$ value, the crack depth was calculated by making the $x$ value of Figure 9 follow the function given below:

$$
y_{1}=2.5 x-2.5,
$$

where $y_{1}$ is the crack depth (refer to Table 4).

4.3. Validation of Empirical Equations. An additional experiment was conducted to verify the empirical equations obtained earlier. The experiment was performed by changing the illuminance from 2 to $467 \mathrm{~lx}$, and Table 5 shows the intensity values of the cracked area according to the illuminance. The experimental results confirmed that the actual crack depth is well matched with the predicted crack depth even at different illuminations as shown in Figure 10. Tables 6 and 7 show the experimental results of the verification on the empirical equations, and the average error of the actual crack depth and the crack depth predicted by the empirical equation was estimated to be less than $15 \%$. This result suggests that the decrease rate of the intensity value by the black body cavity is constant even when the illuminance incident on the cracked area changes and shows that the approximation of the intensity reduction function obtained inductively is done well.

\section{Summary and Conclusion}

In this paper, the method of predicting the crack depth using the intensity values of the crack and its validity was verified, and an image-based noncontact inspection method was proposed. The crack size of the specimen made of stainless steel is $2 \mathrm{~mm}$ in width and $8 \mathrm{~mm}$ in length, and the depth is increased by $2.5 \mathrm{~mm}$ from 0 to $17.5 \mathrm{~mm}$. For a comparison of intensity values of the crack, the specimens were painted with a matte spray, and then a white paper as the contrast index was attached to the center of the crack. In addition, since the intensity value trends according to the depth of the black body cavity vary greatly depending on the direction of the light incident on the specimen, the experimental results were obtained by using the indirect lighting method which shows the most stable results, and the intensity values that decrease with the depth of the black body cavity were formulated inductively. The depth of the specimen was predicted using the obtained intensity reduction equation, and the method is as follows: (1) obtain the intensity values of the uncracked specimen in a limited illumination environment, (2) substitute the initial intensity values into the empirical equation of intensity value reduction according to the crack depth, and (3) predict the crack depth by using the value obtained from (2). In addition, experimental data were secured by varying the illuminance to verify the validity of the empirical equation. As a result, it was found that the average error of the actual crack depth and the crack depth predicted by the empirical equation was about $15 \%$, and the decrease rate of the intensity values according to the depth of the black body cavity was constant even if the illuminance varied. Through these experiments, the validity of the intensity reduction equation obtained by the inductive method was verified, and it was confirmed that the crack depth can be predicted by the intensity value of the cracked area.

\section{Conflicts of Interest}

The authors declare that they have no conflicts of interest.

\section{Acknowledgments}

This research was supported by a grant from the R\&D Program of the Korea Railroad Research Institute, Republic of Korea.

\section{References}

[1] Y. Fujita and Y. Hamamoto, "A robust automatic crack detection method from noisy concrete surfaces," Machine Vision and Applications, vol. 22, no. 2, pp. 245-254, 2011.

[2] L. Wu, S. Mokhtari, A. Nazef, B. Nam, and H.-B. Yun, "Improvement of crack-detection accuracy using a novel crack defragmentation technique in image-based road assessment," Journal of Computing in Civil Engineering, vol. 30, no. 1, p. 04014118, 2014.

[3] I. Abdel-Qader, O. Abudayyeh, and M. E. Kelly, "Analysis of edge-detection techniques for crack identification in bridges," Journal of Computing in Civil Engineering, vol. 17, no. 4, pp. 255-263, 2003.

[4] L. Cartz, Nondestructive Testing, ASM International, Geauga County, OH, USA, 1995.

[5] J. García-Martín, J. Gómez-Gil, and E. Vázquez-Sánchez, "Non-destructive techniques based on eddy current testing," Sensors, vol. 11, no. 3, pp. 2525-2565, 2011.

[6] R. Yang, Y. He, B. Gao, G. Y. Tian, and J. Peng, "Lateral heat conduction based eddy current thermography for detection of parallel cracks and rail tread oblique cracks," Measurement, vol. 66, pp. 54-61, 2015.

[7] X. Li, B. Gao, W. L. Woo, G. Y. Tian, X. Qiu, and L. Gu, "Quantitative surface crack evaluation based on eddy current pulsed thermography," IEEE Sensors Journal, vol. 17, no. 2, pp. 412-421, 2017.

[8] S. Ranjit, K. Kang, and W. Kim, "Investigation of lock-in infrared thermography for evaluation of subsurface defects size and depth," International Journal of Precision Engineering and Manufacturing, vol. 16, no. 11, pp. 2255-2264, 2015.

[9] M. Basheer, P. Ravindran, and K. Balasubramaniam, "A thermographic approach for surface crack depth evaluation 
through 3D finite element modeling," AIP Conference Proceedings, vol. 1650, no. 1, 2015.

[10] J. Qiu, C. Pei, H. Liu, and Z. Chen, "Quantitative evaluation of surface crack depth with laser spot thermography," International Journal of Fatigue, vol. 101, pp. 80-85, 2017.

[11] G. Millerson, Lighting for TV and Film, CRC Press, Boca Raton, FL, USA, 2013.

[12] A. Ryer and Visible Light, Light Measurement Handbook, International Light, Inc., Newburyport, MA, USA, 1997.

[13] O. Gal, Inverse Square Law, Athlone Press, London, UK, 2002. 


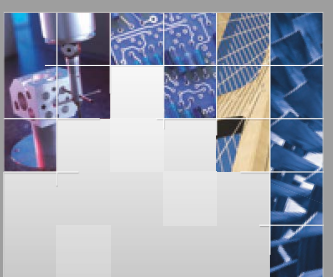

\section{Enfincering}
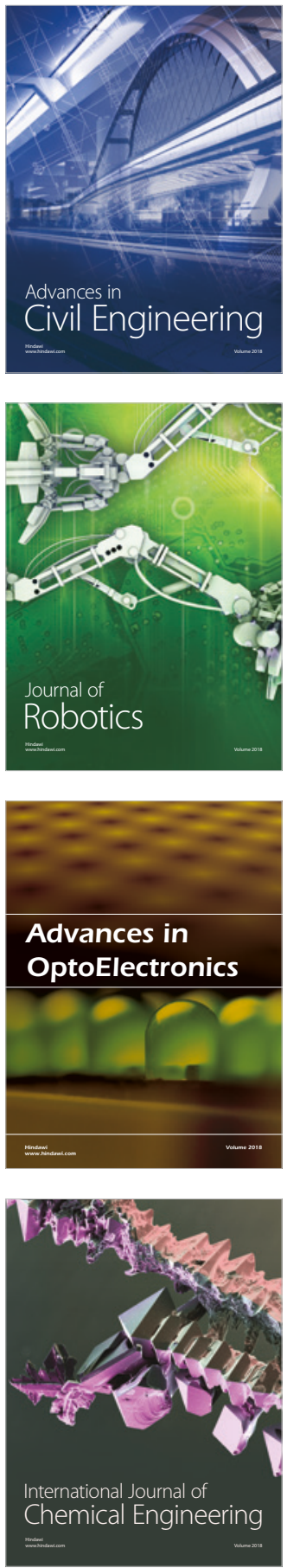

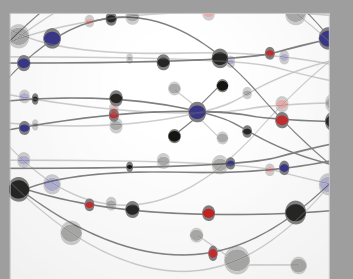

\section{Rotating \\ Machinery}

The Scientific World Journal

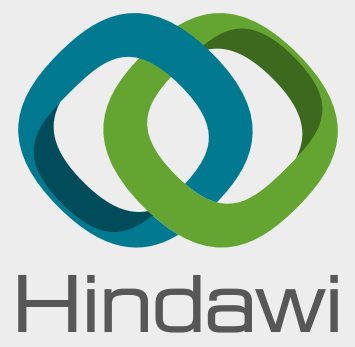

Submit your manuscripts at

www.hindawi.com
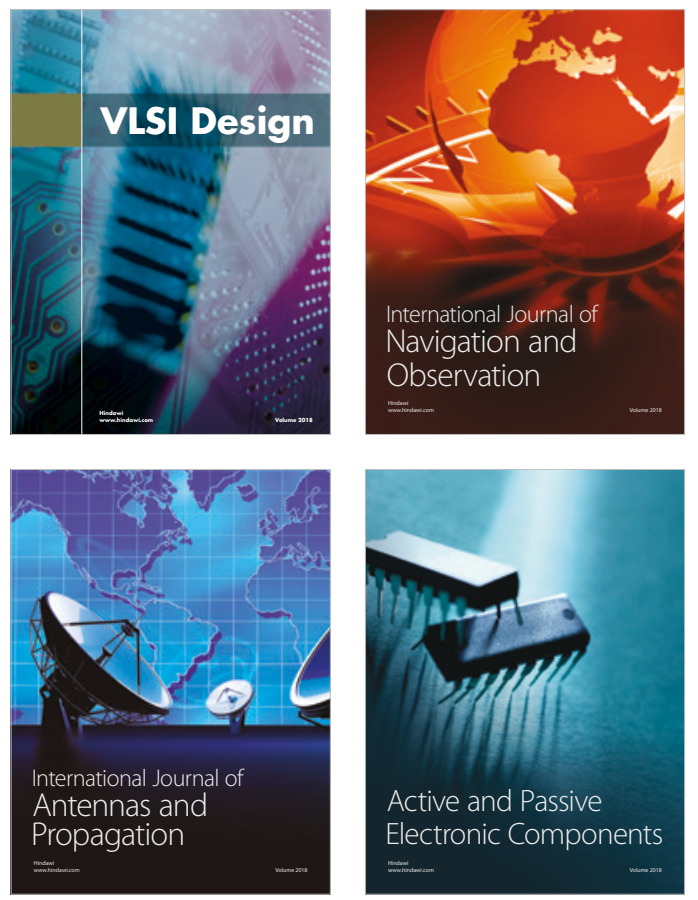
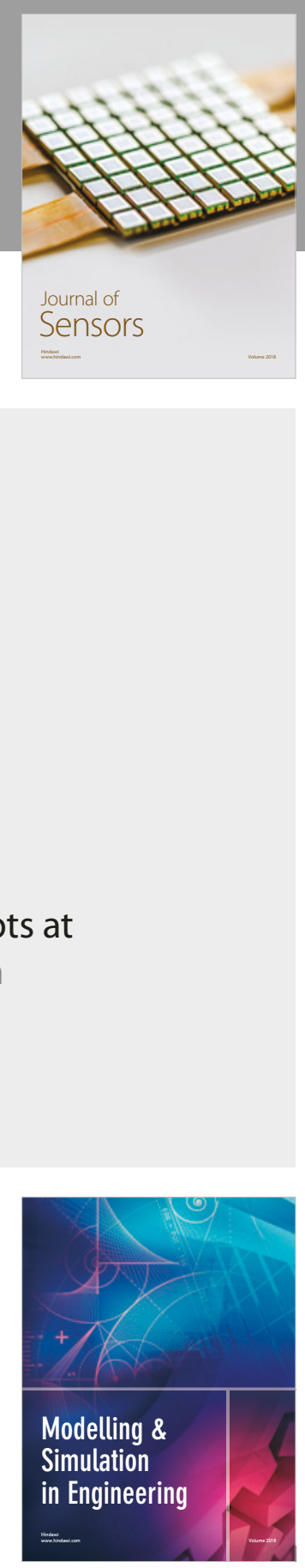

\section{Advances \\ Multimedia}
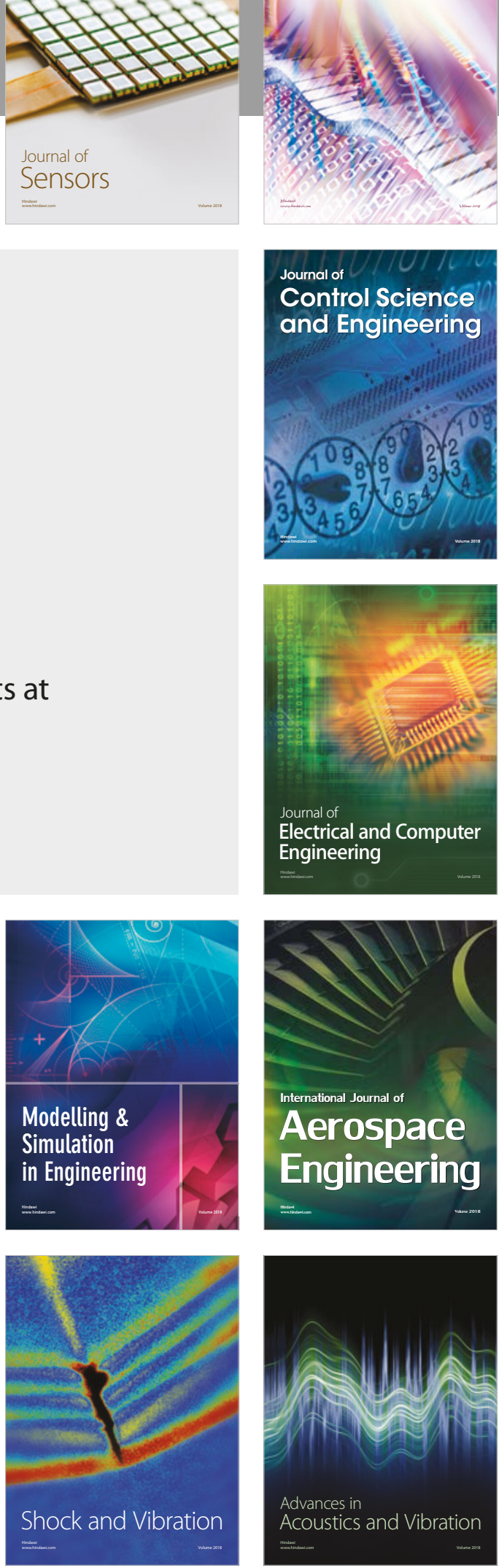